\title{
Secular trends in chronic respiratory diseases mortality in Brazil, Russia, China, and South Africa: a comparative study across main BRICS countries from 1990 to 2019
}

\author{
Jianjun Bai ${ }^{1}$, Yudi Zhao ${ }^{1}$, Donghui Yang ${ }^{1}$, Yudiyang Ma ${ }^{1}$ and Chuanhua $\mathrm{Yu}^{1,2^{*}}$
}

\begin{abstract}
Background: As the emerging economies, the BRICS (Brazil, Russia, India, China, and South Africa) shared 61.58\% of the global chronic respiratory diseases (CRD) deaths in 2017. This study aimed to assess the secular trends in CRD mortality and explore the effects of age, period, and cohort across main BRICS countries.

Methods: Data were obtained from the Global Burden of Disease Study (GBD) 2019 and analyzed using the ageperiod-cohort (APC) model to estimate period and cohort effects between 1990 and 2019. The net drifts, local drifts, longitudinal age curves, period/cohort rate ratios (RRs) were obtained through the APC model.

Results: In 2019, the CRD deaths across the BRICS were 2.39 (95\%UI 1.95 to 2.84) million, accounting for $60.07 \%$ of global CRD deaths. Chronic obstructive pulmonary disease (COPD) and asthma remained the leading causes of CRD deaths. The age-standardized mortality rates (ASMR) have declined across the BRICS since 1990, with the most apparent decline in China. Meanwhile, the downward trends in CRD death counts were observed in China and Russia. The overall net drifts per year were obvious in China (-5.89\%; -6.06\% to $-5.71 \%)$, and the local drift values were all below zero in all age groups for both sexes. The age effect of CRD presented increase with age, and the period and cohort RRs were following downward trends over time across countries. Similar trends were observed in COPD and asthma. The improvement of CRD mortality was the most obvious in China, especially in period and cohort effects. While South Africa showed the most rapid increase with age across all CRD categories, and the period and cohort effects were flat.

Conclusions: BRICS accounted for a large proportion of CRD deaths, with China and India alone contributing more than half of the global CRD deaths. However, the declines in ASMR and improvements of period and cohort effects have been observed in both sexes and all age groups across main BRICS countries. China stands out for its remarkable reduction in CRD mortality and its experience may help reduce the burden of CRD in developing countries.
\end{abstract}

Keywords: Chronic respiratory diseases (CRD), Chronic obstructive pulmonary disease (COPD), Asthma, Mortality, Age-period-cohort model, BRICS

*Correspondence: yuchua@whu.edu.cn

${ }^{2}$ Global Health Institute, Wuhan University, 185\# Donghu Road,

430072 Wuhan, China

Full list of author information is available at the end of the article

\section{Background}

Over the recent decades, epidemiologic evidences have shown that non-communicable diseases $(\mathrm{NCD})$ are being the main contributors to disease burden worldwide [1, 2]. As a crucial category of NCDs, chronic respiratory 
diseases (CRD) have been the third leading cause of deaths globally, ranked behind cardiovascular diseases and cancers [3]. According to Global Burden of Diseases, Injuries, and Risk Factors (GBD) 2019, CRD caused 3.91 million deaths in 2017 [4], which led to a heavy burden on individuals and health systems, especially for low- and middle-income countries.

As the economies coalition composed of developing countries, Brazil, Russia, India, China, and South Africa (BRICS) has undergone the rapid economic expansion, and the consequent population swell, environmental pollution, health resources inequalities, and transition in disease burden to NCDs [5, 6]. Although socioeconomic disparities and CRD prevention of the BRICS countries have improved during the recent years $[7,8]$, the burden of CRD remains heavy across the BRICS, with 2.41 million deaths from CRD in 2017, accounting for $61.58 \%$ of CRD deaths worldwide [9-11]. Given that other developing countries may encounter the similar dilemma along the epidemiological and economic transition, advances in the BRICS health policies and CRD prevention and control is instructive for low- and middleincome countries [12].

To improve people's respiratory health, governments and non-governmental organizations have made great efforts over the past decades. In 2013, BRICS committed to strengthen intra-BRICS cooperation for improving breath health. In 2015, the United Nations adopted Sustainable Development Goals (SDG) target 3.4 to reduce premature mortality from NCDs by a third by 2030 , including CRD [13]. In 2017, BRICS reaffirmed to make efforts to achieve the SDGs 2030[14]. Hence, to better understand the gap between current conditions and SDGs, it is essential to estimate the time trends of the CRD burden over recent period among the BRICS by a comparable manner. To our knowledge, there is no study available giving combined comparison of the disease burden in CRD across the BRICS.

In this study, we adopted the data from GBD 2019 to examine the secular trends of CRD mortality and assessed the effects of age, period, and birth cohort across the BRICS using age-period-cohort (APC) model. Previous analyses have focused on CRD mortality trends over time by age and region, but ignored the accumulation of health risks since birth. Crude mortality calculated by traditional statistical methods is incapable of eliminating or controlling the interaction between age, period, and birth cohort factors. It cannot accurately reflect the actual effect of age, period, and birth cohort on mortality [15]. While assessing the relative contribution of period and cohort effects to overall temporal trends might help determine the efficacy of early policy initiatives and identify future priorities.
The findings of this study may provide new evidence of influencing factors for CRD and help public health managers to assess the impact of previous interventions and formulate further policies.

\section{Methods \\ Data sources}

We obtained the population, deaths, and age-standardized mortality rates (ASMR) data for all age and agestandardized groups across the BRICS from GBD 2019, which provideds comparable and systematic standardized estimations of CRD for 204 countries and territories, by age and sex, from 1990 to 2019. Original data sources for Brazil were primary from the Mortality Information System [10]; for Russia, from center for Demographic Research, New Economic School (Russia) [16]; for China, from censuses, the Disease Surveillance Point system, Maternal and Child Surveillance System, and Chinese Center for Disease Control and Prevention Cause of Death Reporting System [17]; for South Africa, largely from South Africa Vital Registration system and Statistics South Africa [18]. All the relevant estimations are publicly available online and all downloaded from Global Health Data Exchange (GHDx) query tool (http://ghdx. healthdata.org/gbd-results-tool). The Cause of Death Ensemble model (CODEm), a highly systematised tool, was used to estimate mortality based on original data sources and covariates, including socio-demographic Index, lagging distribution income, education, alcohol consumption and so on. DisMod-MR2.1, based on Bayesian meta-regression tool, evaluate the available data and ensure the consistency between epidemiological parameters [2, 19]. CRD and its subtypes (COPD, pneumoconiosis, asthma, interstitial lung disease, and pulmonary sarcoidosis) were defined based on Ninth and Tenth Revision of the International Classification of Diseases $[2,3,19]$. Rates were age-standardized by the GBD 2019 global standard population.

\section{Statistical analysis}

The age-period-cohort (APC) model can evaluate the effect of age, period, and birth cohort on the mortality of chronic diseases and has been widely used to analyze the mortality trends of NCDs [20, 21]. We adopt the APC Web Tool for parameter estimation along with associated statistical hypothesis tests. The tool can be accessed at http://analy-sistools.nci.nih.gov/apc/, and its codes were open at https://github.com/CBIIT/nci-webto ols-dceg-age-period-cohort.

The CRD age-standardized mortality rates were appropriately categorized into consecutive 5 -year periods from 1990 to 2019, successive 5-year age groups from 20 to 24 years to $80-84$ years, and the corresponding consecutive 
18 birth cohorts (1910-1914, 1915-1919, ..., 1995-1999). Besides, we take central age groups (50-54 years), 20002004 period, and 1950-1954 cohort as reference [22, 23].

The following parameters were obtained through the APC model. The net drifts represent the log-linear trends by period and birth cohort, showing the overall estimated annual percentage change in the ASMR. The local drifts represent the log-linear trends by period and birth cohort for specific age groups, indicating estimated annual percentage change over time specific to the age group. The longitudinal age curves represent fitted longitudinal age-specific rates in reference cohort adjusted for period deviations. The period rate ratios (RR) are the ratio of age-specific rates in a specific period relative to the reference period. The cohort rate ratios (RRs) are the ratio of age-specific rates in each cohort relative to reference cohort [24]. The period effects represent variations in different screening methods, medical technology applications, or disease classification standards over specific periods. Cohort effects refer to the long-term trend of disease mortality of those born around the same time, which may be related to lifestyle, external environment, and risk factors exposure.

Since the three parameters of the APC model have exact linear dependency (period=age +cohort), it's difficult to calculate the only model estimator. Therefore, we adopted the APC web tool with the intrinsic estimator method to address the multicollinearity problem[23]. Wald chi-square tests were carried out to verify the significance of estimable parameters and functions (Additional file 1: Supplementary Table 1). We used general linear models to evaluate the interaction terms between sex and calendar year/birth cohort and assess the statistical significance of the slopes for the period/cohort RRs. Statistical analyses were performed using SPSS software.
Statistical significance was considered when a two-sided $\mathrm{p} \leq 0.05$.

\section{Results}

Deaths from CRD

According to the GBD 2019, the total deaths caused by CRD in BRICS were 2.39 (95\%UI 1.95 to 2.84) million in 2019, accounting $60.07 \%$ of the CRD deaths globally (3.97 [3.58 to 4.30] million). Across the BRICS, the deaths of CRD varied considerably, with the most deaths observed in India (1.17 [0.90 to 1.36] million), followed by China (1.09 [0.93 to 1.32 ] million). These two countries recorded $56.71 \%$ of global deaths attributable to CRD in 2019. However from 1990 to 2019, an obvious improvement in deaths was seen in Chinese patients with CRD, whereas patients in India showed worsening health (Fig. 1). Besides, encouraging is that the ASMRs had fallen across the BRICS, with the most apparent decline in China, from 226.43 (95\%UI 170.16 to 251.43) to 67.98 (57.80 to 83.43 ) per 100,000 , followed by Russia.

COPD and asthma remained the two leading causes of CRD deaths during study period (Additional file 3: Supplementary Fig. 1). In 2019, 2.05 (1.68 to 2.46) million people died from COPD and 232.85 (158.12 to 313.84) thousand deaths caused by asthma across the BRICS, accounting for $86.00 \%$ and $9.75 \%$ of the total number of deaths from CRD in BRICS.

\section{Net drifts and local drifts for CRD mortality across the BRICS}

The net drifts were similar in Brazil $(-2.24 \%$, 95\% CI $-2.31 \%$ to $-2.17 \%)$ and South Africa $(-2.33 \%,-2.68 \%$ to $-1.97 \%)$. The net drifts in China and Russia were $-5.89 \%$ $(-6.06 \%$ to $-5.71 \%)$ and $-3.82 \%$ (-4.08\% to $-3.56 \%)$, representing the relatively more significant reductions in CRD
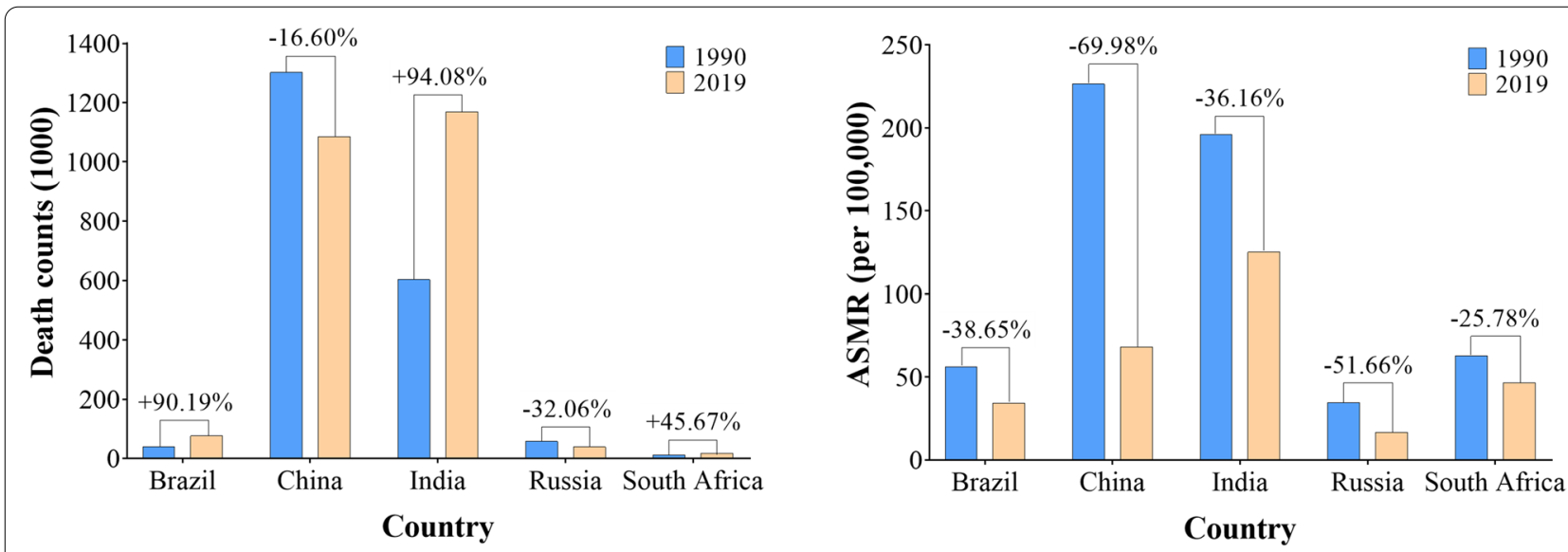

Fig. 1 The CRD deaths, age-standardized mortality rates (ASMR) and percentage changes across BRICS countries 
mortality. Also, the CRD mortality for both sexes had achieved relatively great improvement across countries (Table 1).

The local drifts were all below zero by age group among four countries, indicating the improvements in CRD mortality. And the most remarkable progress was detected in China for all age groups. The most impressive improvements were for Chinese aged 55 to 59 (-6.45\%), Russian aged 55 to $59(-4.67 \%)$, Brazilian aged 50 to 54 $(-2.23 \%)$, and South African aged 20 to $24(-5.13 \%)$. The local drifts by sex were similar to the overall trends (Additional file 2: Supplementary Table 2).

\section{The age, period, and cohort effects on CRD mortality}

Figure 2 illustrates the longitudinal age curves of sexspecific CRD mortality. After controlling for period and cohort effects, we found that the distribution of CRD mortality with age exhibited exponential distribution. The CRD mortality showed the rapidly expanding trends from 45 to 49 age group to 80-84 age group. Among the four countries, South Africa showed the steepest increases with age, from 10.27 to 734.64 per 100,000 , followed by China. In comparison, the increase of CRD mortality in Russia was relatively moderate, from 2.40 to 105.72 per 100,000 . In each age group, the CRD mortality of males were higher than those of females in China,
Russia, and South Africa $(\mathrm{P}<0.05)$. The sex disparity of mortality gradually increased with age.

The estimated period RRs showed prominent downward trends for both sexes across four countries (Fig. 2). The most obvious improvement of CRD risk was detected in China, with period RRs decreasing from 1.72 to 0.39 , followed by Russia, from 1.37 to 0.57 . Besides, the improvements in CRD risk were more significant for Chinese females. Similarly, the estimated cohort RRs followed the monotonic decreasing trends for both sexes across countries, especially for Chinese females, decreased from 10.17 in 1910 to 0.04 in 1995 . For China and Russia, the improvements in CRD risk were noticeable for people born before 1960. The advances in Brazil and South Africa were relatively minor but favorable. For South Africa, the period and cohort effects were flat. The cohort RRs were statistically significant for both sexes in four countries based on the results of the general linear model $(\mathrm{P}<0.001$ for all $)$.

\section{The age, period, and cohort effects on CRD subtype mortality}

COPD was the major contributor to CRD mortality across four countries, and the distribution of COPD mortality with age exhibited the characteristic exponential distribution (Fig. 3). The COPD mortality in South Africa showed the fastest increase with age, reaching the peak of

Table 1 The net drifts and local drifts for Brazil, China, Russia, and South Africa (\%)

\begin{tabular}{|c|c|c|c|c|}
\hline \multirow[t]{2}{*}{ Sex } & \multicolumn{4}{|l|}{ Net drifts ${ }^{\mathrm{a}}(95 \% \mathrm{Cl})$} \\
\hline & Brazil & China & Russia & South Africa \\
\hline Both & $-2.24(-2.31,-2.17)$ & $-5.89(-6.06,-5.71)$ & $-3.82(-4.08,-3.56)$ & $-2.33(-2.68,-1.97)$ \\
\hline Male & $-2.32(-2.41,-2.23)$ & $-5.24(-5.4,-5.08)$ & $-3.99(-4.31,-3.67)$ & $-2.13(-2.41,-1.84)$ \\
\hline Female & $-2.07(-2.13,-2.02)$ & $-6.89(-7.2,-6.57)$ & $-3.57(-3.8,-3.34)$ & $-2.49(-3.00,-1.98)$ \\
\hline \multirow[t]{2}{*}{ Age } & \multicolumn{4}{|l|}{ Local drifts ${ }^{\mathrm{a}}(95 \% \mathrm{Cl})$} \\
\hline & Brazil & China & Russia & South Africa \\
\hline $20-24$ & $-1.90(-2.34,-1.46)^{a}$ & $-5.93(-7.54,-4.29)$ & $-4.09(-6.54,-1.57)$ & $-5.13(-7.35,-2.85)$ \\
\hline $25-29$ & $-2.15(-2.46,-1.84)^{\mathrm{a}}$ & $-6.20(-7.14,-5.25)$ & $-3.33(-4.70,-1.94)$ & $-4.86(-6.20,-3.49)$ \\
\hline $30-34$ & $-2.33(-2.57,-2.10)^{\mathrm{a}}$ & $-6.00(-6.68,-5.32)$ & $-2.91(-3.84,-1.97)$ & $-4.04(-5.06,-3.00)$ \\
\hline $35-39$ & $-2.38(-2.57,-2.18)$ & $-5.92(-6.43,-5.40)$ & $-3.10(-3.81,-2.39)$ & $-3.31(-4.19,-2.43)$ \\
\hline $40-44$ & $-2.33(-2.48,-2.17)$ & $-5.94(-6.30,-5.58)$ & $-3.75(-4.32,-3.19)$ & $-2.84(-3.60,-2.08)$ \\
\hline $45-49$ & $-2.25(-2.37,-2.12)$ & $-6.13(-6.38,-5.87)$ & $-4.28(-4.71,-3.84)$ & $-2.61(-3.28,-1.94)$ \\
\hline $50-54$ & $-2.23(-2.33,-2.13)$ & $-6.37(-6.57,-6.18)$ & $-4.56(-4.87,-4.25)$ & $-2.18(-2.75,-1.60)$ \\
\hline $55-59$ & $-2.29(-2.37,-2.21)$ & $-6.45(-6.61,-6.30)$ & $-4.67(-4.89,-4.45)$ & $-1.50(-2.00,-1.00)$ \\
\hline $60-64$ & $-2.36(-2.43,-2.29)$ & $-6.12(-6.23,-6.01)$ & $-4.50(-4.67,-4.32)$ & $-1.11(-1.56,-0.66)$ \\
\hline $65-69$ & $-2.32(-2.38,-2.26)$ & $-5.71(-5.80,-5.62)$ & $-3.89(-4.05,-3.74)$ & $-0.88(-1.28,-0.47)$ \\
\hline $70-74$ & $-2.16(-2.21,-2.11)$ & $-5.23(-5.30,-5.16)$ & $-3.10(-3.26,-2.94)$ & $-1.04(-1.43,-0.66)$ \\
\hline $75-79$ & $-2.00(-2.06,-1.95)$ & $-4.72(-4.79,-4.66)$ & $-2.57(-2.73,-2.41)$ & $-1.10(-1.51,-0.68)$ \\
\hline $80-84$ & $-1.97(-2.04,-1.90)$ & $-4.23(-4.31,-4.14)$ & $-2.69(-2.89,-2.49)$ & $-1.28(-1.84,-0.73)$ \\
\hline
\end{tabular}

Note: ${ }^{\text {a }} \mathrm{Cl}$ confidence interval; Net drifts represent the overall annual percentage change in the age-standardized rate based on period and birth cohort. Local drifts indicate the annual percentage change over time specific to the age group. All of Net drifts and Local drifts were statistically significant $(p<0.05)$. India was excluded because India's data didn't meet the APC model's requirements 

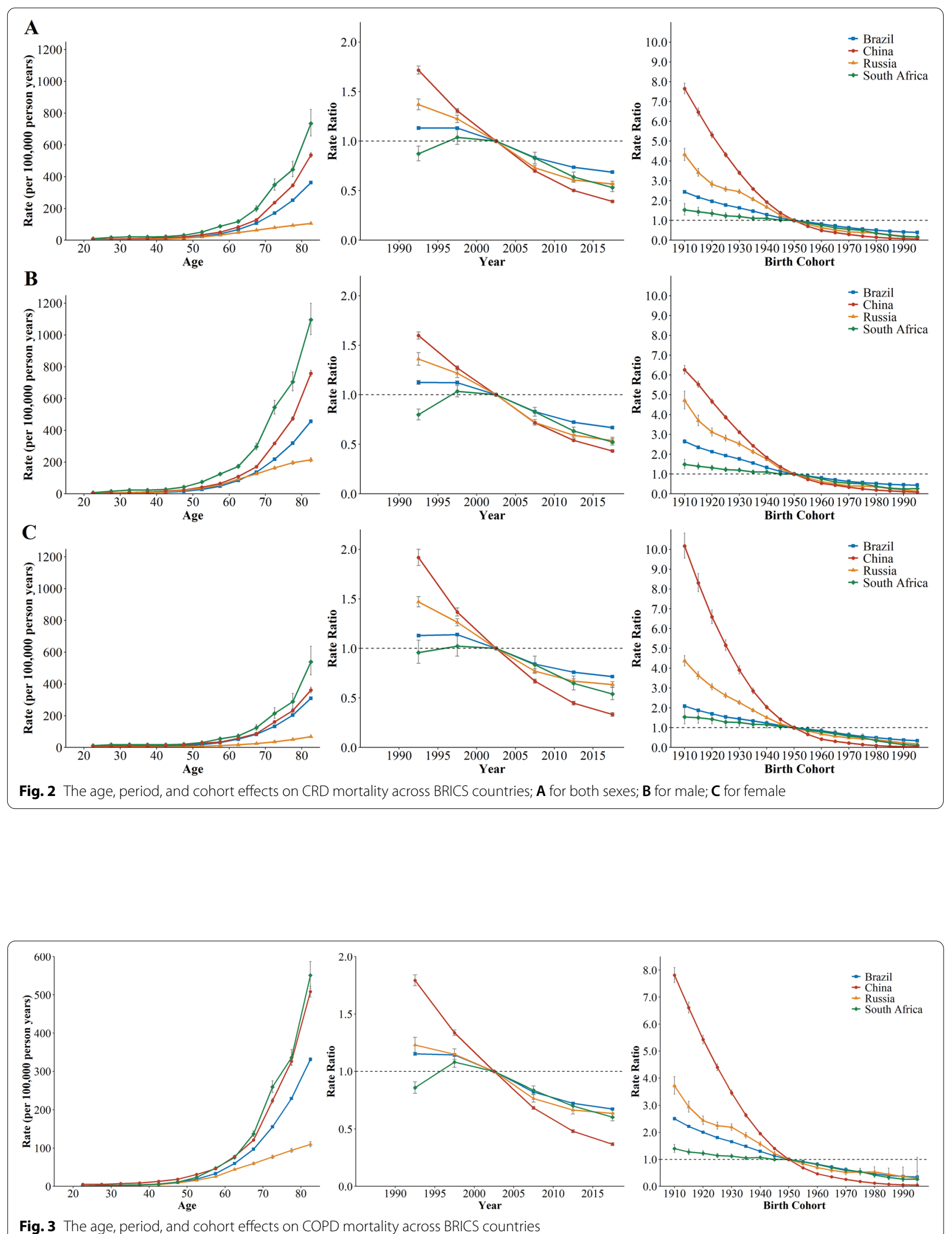

Fig. 3 The age, period, and cohort effects on COPD mortality across BRICS countries 

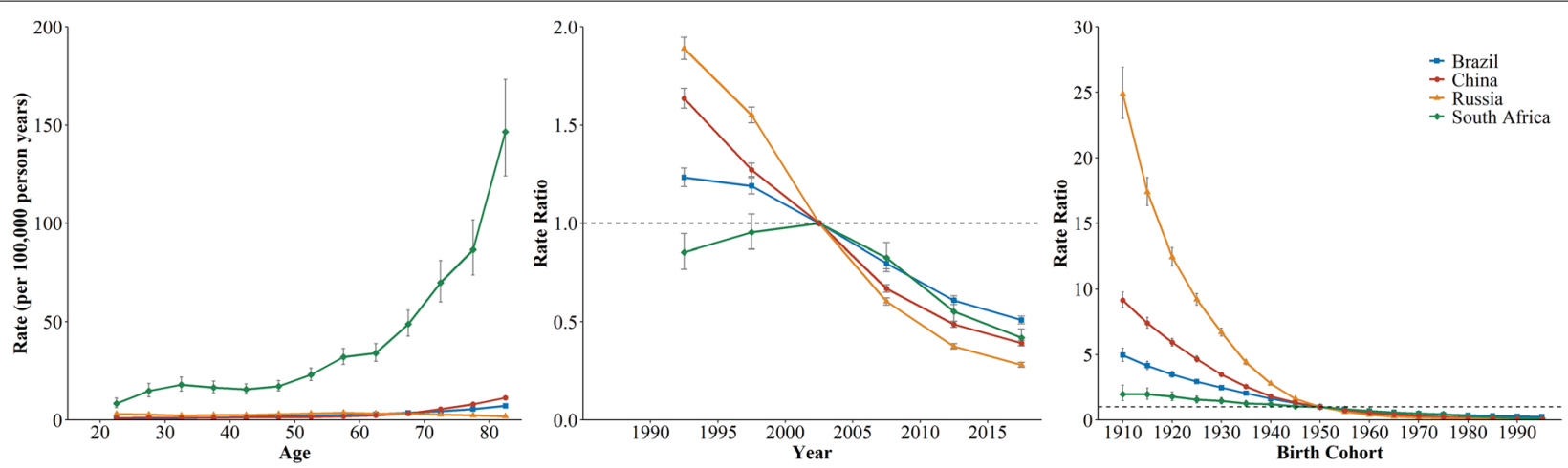

Fig. 4 The age, period, and cohort effects on asthma mortality across BRICS countries

551.05 per 100,000 at the $80-84$ age group. Similar trend was observed in China, climbing from 5.11 to 508.16 per 100,000 . Russia showed a relatively moderate increase in COPD mortality. As for period RRs, the most obvious improvement was observed in China, decreasing from 1.79 to 0.37 . Russia and Brazil performed similarly and favorably on improvement of period effects. Likewise, the decline of cohort RRs was the most dramatic in China, from 7.82 in 1910 to 0.05 in 1995, followed by Russia, from 3.72 to 0.30 .

As for the second contributor to CRD mortality, the fastest increase of asthma mortality was detected in South Africa, from 8.43 to 146.60 per100,000 (Fig. 4). In China and Brazil, the increase in asthma mortality with age was not obvious. While the asthma mortality in Russia showed the decreasing trend after age 55, falling to 1.89 per 100,000 at the $80-84$ age group. During the study period, the period and cohort RRs of asthma mortality decreased across four countries. And the declining trends of period and cohort RRs in Russia was most dramatic, followed by China. While the declining trends of asthma in South Africa was flat.

For interstitial lung disease and pulmonary sarcoidosis, the age effect showed a continuous upward trend. South Africa had the highest mortality across all age groups, as well as Brazil. Among four countries, the period and cohort effects were flat, suggesting no improvements for the whole population over study period (Additional file 4: Supplementary Fig. 2). For pneumoconiosis, Russia was excluded since the data didn't meet the requirements. The age effect showed a continuous upward trend with age. South Africa had surpassed China as the country with the highest mortality after the 50-54 age group. For period and cohort RRs, China had a more pronounced downward trend, which indicated the improvement of pneumoconiosis risk in China (Additional file 5: Supplementary Fig. 3).

\section{Discussion}

According to GBD 2019, CRD caused 3.97 (95\% CI 3.58 to 4.30) million deaths worldwide, ranking behind cardiovascular diseases and cancers. The BRICS account for a large proportion of global CRD deaths, and China and India alone have contributed over half of global CRD deaths in 2019. However, encouraging is that the improvements in ASMRs have been seen since 1990 across the BRICS. Meanwhile, declines in CRD deaths have been detected in China and Russia over the study period.

Within the BRICS, there were striking differences between countries both in rates and secular trends. India had the most CRD deaths and the highest CRD mortality in recent years. Meanwhile, with the population growing and aging, the number of CRD deaths in India continued to rise during the study period. Although the improvements in ASMRs have been observed, but CRD burden per person in India was still higher than the global average level [25]. Evidences suggested that the higher CRD burden in India was partly due to late diagnosis and poor management [26-28]. Insufficient clinical knowledge of COPD and asthma, mainly symptom-based diagnosis, inadequate use of gold standard, and overlapping clinical features lead to underdiagnosis or misdiagnosis of CRD in India [26, 27]. Meanwhile, the acceptance of inhaled drugs is relatively low in India $[29,30]$. Regional disparities and socioeconomic status disparities also pose challenges to the prevention and treatment of CRD in India.

The greater period and cohort improvements have been observed in China across all categories of CRD mortality, especially for COPD and asthma. China's investment in health is likely to be a major factor. Over the study period, the enhanced diagnosis, treatment techniques, better access to basic public health services, the new rural cooperative medical system, and the reform of CRD healthcare costs have contributed to improvement 
of CRD mortality in China[31, 32]. Besides, for main risk factors of CRD, air pollution and tobacco, Chinese government has adopted a series of control measures. Ambient air pollution in most areas of China has gradually improved[33], and exposure reduction of ambient and indoor air pollution were also observed among rural areas[34]. Meanwhile chinese smoking prevalence has declined since 1990 in both sexes [35]. Although favorable decling trends in deaths have been observed, due to population growth and aging, the number of CRD deaths was still higher across the BRCIS. For note, huge population size, rapid aging population, relatively large smoking population, and regional and sex disparities should receive more attention with supportive policies to lessen the premature CRD mortality in China.

Russia had a lower baseline CRD mortality level, and the improvements of period and cohort effects were impressive. The number of CRD deaths and ASMR in Russia both declined from 1990 to 2019. The gains were the result of period and cohort effects, and Russia's reform in health care may be a main factor. Since 1993, mandatory health insurance reform and pharmaceutical policy reform have focused on improving access and equality to health care, which contributed to the early detection and treatment of CRD [36-38]. Besides, for the major risk factor, Russia has adopted stricter prevention and control measures against smoking. Some studies have predicted that the smoking prevalence in Russia would decrease by as much as $50 \%$ by 2055 if the current policies remain unchanged [39, 40]. Meanwhile, given the high correlation between CRD and CVD, intervention in CRD would help reduce the overall disease burden in Russia [41]. However, aging, COPD misdiagnosis, a high proportion of undiagnosed patients, low adherence to treatment, and exposure to occupational risk factors impede further advance in breath health for Russia $[16,42]$.

From 1990 to 2019, CRD deaths in Brazil rose mainly due to population growth and ageing process, while the trend in CRD mortality declined with improvement over period and birth cohorts. In 1994, Brazil launched the Family Health Program (FHP) and promoted it throughout the country; both the FHP and the subsequent strategies have contributed to prevention, diagnosis, and treatment of NCDs [43]. In 2006, Brazil joined the GARD and provided an excellent platform for CRD preventing and controlling [44]. For smoking, Brazil issued Framework Convention on Tobacco Control in 2006, the Smoke-Free Law in 2014 and subsequent tobacco control policies to reduce tobacco consumption. The tobacco use prevalence decrease by roughly 60\% from 1998 to 2013 [45]. As for COPD and asthma,
Brazil strengthened the training of general practitioners working at the community level and announced to provide non-paying treatment for severe asthmatic patients and health care facilities, education, and free medication for all asthmatics[44]. For note, with rapid industrialization and urbanization in Brazil, air pollution and occupational exposure are becoming more serious. This would increase the risk of CRD and impact those with pre-existing conditions [10].

The ASMR of CRD in South Africa showed a downward trend; however, compared with other BRICS countries, the period and cohorts effect in South Africa were flat. Over the past years, South Africa has concentrated resources on the treatment of infectious diseases such as AIDS and tuberculosis, and these investments seem to have been rewarded, the increase in life expectancy was observed, but the burden of NCDs has not been contained [46, 47]. Besides, another concern related to CRD in South Africa was aging; with the rapidly growing population aged 60 years and older, aging would lead to dramatic changes in patterns of disease burden and increase the risk of respiratory diseases in South Africa [48, 49]. Furthermore, HIV patients have a higher risk of respiratory diseases among children and adults [50]. Since 1994, South African has committed to promoting tobacco control, but the effect is scant [51]; smoking prevalence has been rising between 2008 and 2011 [52]. Additionally, occupational risk factors have also been major problems in sub-Saharan Africa [53]. Mine-related facilities are the primary source of airborne particulate matter and metals pollution, which would seriously affect the respiratory health of workers and surrounding residents [54, 55]. So from 1973, many efforts have been made up, like the Surveillance of Work-related and Occupational Respiratory Diseases, the South Africa Occupational Diseases in Mines and Works Act, and the Mine Health and Safety Act $[56,57]$. Meanwhile, education and training for primary care nurses in South Africa would help them better cope with CRD and has been implemented in primary care clinics across South Africa [58].

There are several limitations to our study. Frist, because the period and age intervals should be fixed and equal in the APC tool, data of people aged $\geq 85$ years could not be analyzed because of the data availability (they were designated as one age group in GBD database). But substantially higher mortality of CRD happens in seniors aged $\geq 85$ years. While in our study, age group-specific annual percent changes over time maintained less than zero, which was just more moderate than that of younger groups. And we could confirm to a certain extent that the declining trends in CRD mortality would remain among seniors aged $\geq 85$ years across BRICS. Meanwhile, 
previous studies confirmed that the CRD mortality of those aged $\geq 85$ years is decreasing in a similar pattern $[4,10,59]$. Second, GBD studies provide comparable and systematic standardized estimates of global CRD burden, while data on cause of death record, medical death certificate, primary cause of death identification are not available for GBD 2019, which are also references for the comparison of CRD mortality between countries [60-62]. Third, it is evitable that the completeness and accuracy on primary CRD data may cause bias, although many adjusted methods have been conducted by GBD to reduce such bias. Finally, the APC model is based on the population level, so ecological fallacy might occur, the interpretation of the study might not apply to the individual level.

\section{Conclusions}

The burden of chronic respiratory disease remains heavy among the BRICS, with China and India alone contributing more than half of the global CRD deaths. While the ASMRs, period effects, and cohort effects have been declining both in sexes and all age groups from 1990 to 2019. Similar downward trends were observed for the two main subtypes, COPD and asthma. Meanwhile, the age effects suggest that more attention should be paid to the middle-aged and elderly. Among BRICS, China stands out for its remarkable reduction in CRD mortality over time, both in recent birth cohorts and across all age groups. Its example may offer experience for other developing countries in reducing the burden of CRD with rapid economic development.

\section{Abbreviations}

CRD: Chronicrespiratory diseases; COPD: Chronicobstructive pulmonary disease; BRICS: Brazil,Russia, India, China, and South Africa; NCD: Non-communicablediseases; APC: Age-period-cohort; ASMR: Age-standardizedmortality rates; RR: Rateratios; ICD : InternationalClassification of Diseases; SDG: SustainableDevelopment Goals; GBD: GlobalBurden of Diseases, Injuries, and Risk Factors; GHDx: GlobalHealth Data Exchange ; GARD: GlobalAlliance against Chronic Respiratory Diseases.

\section{Supplementary Information}

The online version contains supplementary material available at https://doi. org/10.1186/s12889-021-12484-Z

Additional file 1: Supplementary table 1. Wald Chi Square tests for estimable functions in the APC model.

Additional file 2: Supplementary table 2. The local drifts (\%) for Brazil, China, Russia, and South Africa by sex.

Additional file 3: Supplementary figure 1. Proportion of deaths by CRD subtypes between 1990 and 2019.

Additional file 4: Supplementary figure 2. The age, period, and cohort effects on interstitial lung disease mortality across main BRICS countries.

Additional file 5: Supplementary figure 3. The age, period, and cohort effects on pneumoconiosis mortality across main BRICS countries.
Acknowledgements

We appreciate the works by the Global Burden of Disease study 2019 collaborators.

\section{Authors' contributions}

$J B$ and $C Y$ conceptualized the analysis. JB and $Y Z$ did the data analysis. JB wrote the first draft of the paper. JB and DY have done the revisions. JB, YZ, DY and YM reviewed and provided comments on the first\& revised draft. All authors reviewed and approved the final manuscript.

\section{Funding}

This research was funded by the National Key Research and Development Program of China (2018YFC1315302); the National Natural Science Foundation of China (81773552).

\section{Availability of data and materials}

The datasets generated and/or analysed during the current study are available in the Global Health Data Exchange (GHDx) repository, [http://ghdx.healt hdata.org/gbd-results-tool]

\section{Declarations}

Ethics approval and consent to participate

Not applicable.

Consent for publication

Not applicable.

\section{Competing interests}

The authors declare that they have no competing interests.

\section{Author details}

${ }^{1}$ Department of Epidemiology and Biostatistics, School of Public Health, Wuhan University, 185\# Donghu Road, 430072 Wuhan, China. ${ }^{2}$ Global Health Institute, Wuhan University, 185\# Donghu Road, 430072 Wuhan, China.

Received: 1 September 2021 Accepted: 28 December 2021

Published online: 13 January 2022

\section{References}

1. Diem G, Brownson RC, Grabauskas V, Shatchkute A, Stachenko S. Prevention and control of noncommunicable diseases through evidence-based public health: implementing the NCD 2020 action plan. Glob Health Promot. 2016;23(3):5-13.

2. Mortality GBD, Causes of Death C. Global, regional, and national life expectancy, all-cause mortality, and cause-specific mortality for 249 causes of death, 1980-2015: a systematic analysis for the Global Burden of Disease Study 2015. Lancet. 2016;388(10053):1459-544.

3. Disease GBD, Injury I, Prevalence C. Global, regional, and national incidence, prevalence, and years lived with disability for 354 diseases and injuries for 195 countries and territories, 1990-2017: a systematic analysis for the Global Burden of Disease Study 2017. Lancet. 2018;392(10159):1789-858.

4. Collaborators GBDCRD. Prevalence and attributable health burden of chronic respiratory diseases, 1990-2017: a systematic analysis for the Global Burden of Disease Study 2017. Lancet Respir Med. 2020;8(6):585-96

5. Acharya S, Barber SL, Lopez-Acuna D, Menabde N, Migliorini L, Molina J, Schwartlander B, Zurn P. BRICS and global health. Bull World Health Organ. 2014;92(6):386-386A.

6. Jesus TS, Landry MD, Hoenig H, Zeng Y, Kamalakannan S, Britto RR, Pogosova N, Sokolova O, Grimmer K, Louw QA: Physical Rehabilitation Needs in the BRICS Nations from 1990 to 2017: Cross-National Analyses Using Data from the Global Burden of Disease Study. Int J Environ Res Public Health. 2020;17(11):4139.

7. Petrie D, Tang KK. Relative health performance in BRICS over the past 20 years: the winners and losers. Bull World Health Organ. 2014;92(6):396-404 
8. Harmer A, Fleck F. The BRICS countries: a new force in global health? Bull World Health Organ. 2014;92(6):394-5.

9. Salvi S, Kumar GA, Dhaliwal RS, Paulson K, Agrawal A, Koul PA, Mahesh PA, Nair S, Singh V, Aggarwal AN, et al. The burden of chronic respiratory diseases and their heterogeneity across the states of India: the Global Burden of Disease Study 1990-2016. Lancet Global Health. 2018;6(12):E1363-74.

10. Leal LF, Cousin E, Bidinotto AB, Sganzerla D, Borges RB, Malta DC, Ikuta K, Pizzol T. Epidemiology and burden of chronic respiratory diseases in Brazil from 1990 to 2017: analysis for the Global Burden of Disease 2017 Study. Rev Bras Epidemiol. 2020;23:e200031.

11. Zhu B, Wang Y, Ming J, Chen W, Zhang L. Disease burden of COPD in China: a systematic review. Int J Chron Obstruct Pulmon Dis. 2018;13:1353-64.

12. Barbosa da Silva Junior J, Desiraju K, Matsoso P, Minghui R, Salagay O. BRICS cooperation in strategic health projects. Bull World Health Organ. 2014;92(6):388

13. collaborators NCDC. NCD Countdown 2030: pathways to achieving Sustainable Development Goal target 3.4. Lancet. 2020;396(10255):918-34.

14. McBride B, Hawkes S, Buse K. Soft power and global health: the sustainable development goals (SDGs) era health agendas of the G7, G20 and BRICS. BMC Public Health. 2019;19(1):815.

15. Wen H, Xie C, Wang L, Wang F, Wang Y, Liu X, Yu C: Difference in LongTerm Trends in COPD Mortality between China and the U.S., 1992(-)2017: An Age(-)Period(-)Cohort Analysis. Int J Environ Res Public Health. 2019;16(9):1529.

16. Collaborators GBDR. The burden of disease in Russia from 1980 to 2016: a systematic analysis for the Global Burden of Disease Study 2016. Lancet. 2018;392(10153):1138-46.

17. Zhou M, Wang H, Zeng X, Yin P, Zhu J, Chen W, Li X, Wang L, Wang L, Liu $Y$, et al. Mortality, morbidity, and risk factors in China and its provinces, 1990-2017: a systematic analysis for the Global Burden of Disease Study 2017. Lancet. 2019;394(10204):1145-58.

18. Pillay-van Wyk V, Msemburi W, Laubscher R, Dorrington RE, Groenewald P, Glass T, Nojilana B, Joubert JD, Matzopoulos R, Prinsloo M, et al. Mortality trends and differentials in South Africa from 1997 to 2012: second National Burden of Disease Study. Lancet Glob Health. 2016:4(9):e642-653.

19. Diseases GBD, Injuries C. Global burden of 369 diseases and injuries in 204 countries and territories, 1990-2019: a systematic analysis for the Global Burden of Disease Study 2019. Lancet. 2020;396(10258):1204-22.

20. Yang Y. Trends in U.S. adult chronic disease mortality, 1960-1999: age, period, and cohort variations. Demography. 2008;45(2):387-416.

21. Chia-Wen, Ko: Age-Period-Cohort Analysis: New Models, Methods, and Empirical Applications. Jasa J Am Stat Assoc. 2014;109(506):865.

22. Wang $\mathrm{P}, \mathrm{Xu} \mathrm{C}, \mathrm{Yu} \mathrm{C}$. Age-period-cohort analysis on the cancer mortality in rural China: 1990-2010. Int J Equity Health. 2014;13:1.

23. Cao J, Eshak ES, Liu K, Gero K, Liu Z, Yu C. Age-Period-Cohort Analysis of Stroke Mortality Attributable to High Sodium Intake in China and Japan. Stroke. 2019;50(7):1648-54.

24. Rosenberg PS, Check DP, Anderson WF. A web tool for age-periodcohort analysis of cancer incidence and mortality rates. Cancer Epidemiol Biomarkers Prev. 2014;23(11):2296-302.

25. India State-Level Disease Burden Initiative CRDC. The burden of chronic respiratory diseases and their heterogeneity across the states of India: the Global Burden of Disease Study 1990-2016. Lancet Glob Health. 2018;6(12):e1363-74.

26. Salvi S, Agrawal A. India needs a national COPD prevention and control programme. J Assoc Physicians India. 2012;60:5-7.

27. Gupta D, Agarwal R, Aggarwal AN, Maturu VN, Dhooria S, Prasad KT, Sehgal IS, Yenge LB, Jindal A, Singh N, et al. Guidelines for diagnosis and management of chronic obstructive pulmonary disease: Joint ICS/ NCCP (I) recommendations. Lung India. 2013;30(3):228-67.

28. Salvi SS, Apte KK, Dhar R, Shetty P, Faruqi RA, Thompson PJ, Guleria R. Asthma Insights and Management in India: Lessons Learnt from the Asia Pacific - Asthma Insights and Management (AP-AIM) Study. J Assoc Physicians India. 2015;63(9):36-43.

29. Benton MJ, Lim TK, Ko FWS, Kan OK, Mak JCW. Year in review 2017: Chronic obstructive pulmonary disease and asthma. Respirology. 2018;23(5):538-45.
30. Vanjare N, Chhowala S, Madas S, Kodgule R, Gogtay J, Salvi S. Use of spirometry among chest physicians and primary care physicians in India. NPJ Prim Care Respir Med. 2016;26:16036.

31. Yip WC, Hsiao WC, Chen W, Hu S, Ma J, Maynard A. Early appraisal of China's huge and complex health-care reforms. Lancet. 2012;379(9818):833-42.

32. Tang YM, Liu XN, Zhang QJ, Pan JJ, He TJ, Li Q, Yu CH, Zhang L. Chronic obstructive pulmonary disease deaths, disability-adjusted life years, and risk factors in Hubei province of mid-China, 1990-2015: the Global Burden of Disease Study 2015. Public Health. 2018;161:12-9.

33. Wang S, Xing J, Zhao B, Jang C, Hao J. Effectiveness of national air pollution control policies on the air quality in metropolitan areas of China. J Environ Sci (China). 2014;26(1):13-22.

34. Meng W, Zhong $Q$, Chen Y, Shen H, Yun X, Smith KR, Li B, Liu J, Wang X, $\mathrm{Ma}$ J, et al. Energy and air pollution benefits of household fuel policies in northern China. Proc Natl Acad Sci U S A. 2019;116(34):16773-80.

35. Wen H, Xie C, Wang F, Wu Y, Yu C. Trends in Disease Burden Attributable to Tobacco in China, 1990-2017: Findings From the Global Burden of Disease Study 2017. Front Public Health. 2020;8:237.

36. Rao KD, Petrosyan V, Araujo EC, McIntyre D. Progress towards universal health coverage in BRICS: translating economic growth into better health. Bull World Health Organ. 2014;92(6):429-35.

37. Rudisill C, Vandoros S, Antoun JG. Pharmaceutical policy reform in the Russian Federation. J Health Polit Policy Law. 2014;39(3):691-705.

38. Marten R, McIntyre D, Travassos C, Shishkin S, Longde W, Reddy S, Vega J. An assessment of progress towards universal health coverage in Brazil, Russia, India, China, and South Africa (BRICS). Lancet. 2014;384(9960):2164-71.

39. Giovino GA, Mirza SA, Samet JM, Gupta PC, Jarvis MJ, Bhala N, Peto R, Zatonski W, Hsia J, Morton J, et al. Tobacco use in 3 billion individuals from 16 countries: an analysis of nationally representative cross-sectional household surveys. Lancet. 2012;380(9842):668-79.

40. Maslennikova GY, Oganov RG, Boytsov SA, Ross H, Huang AT, Near A, Kotov A, Berezhnova I, Levy DT. Russia SimSmoke: the long-term effects of tobacco control policies on smoking prevalence and smokingattributable deaths in Russia. Tob Control. 2014;23(6):484-90.

41. Mullerova H, Agusti A, Erqou S, Mapel DW. Cardiovascular comorbidity in COPD: systematic literature review. Chest. 2013;144(4):1163-78.

42. Arkhipov V, Arkhipova D, Miravitlles M, Lazarev A, Stukalina E. Characteristics of COPD patients according to GOLD classification and clinical phenotypes in the Russian Federation: the SUPPORT trial. Int J Chron Obstruct Pulmon Dis. 2017;12:3255-62.

43. Cesar PAM, Liberal MMC, Marvulle V, Zucchi P. Analysis of the indicators of the Family Health Program in the Metropolitan Region of Sao Paulo. Einstein (Sao Paulo). 2018;16(3):eGS4174.

44. Jardim JR, Nascimento O. Respiratory health in Brazil. Chron Respir Dis. 2007;4(1):45-9.

45. Malta DC, Silva AGD, Machado IE, Sa A, Santos FMD, Prates EJS, Cristo EB. Trends in smoking prevalence in all Brazilian capitals between 2006 and 2017. J Bras Pneumol. 2019;45(5):e20180384.

46. Holmes MD, Dalal S, Volmink J, Adebamowo CA, Njelekela M, Fawzi WW, Willett WC, Adami HO. Non-communicable diseases in sub-Saharan Africa: the case for cohort studies. PLoS Med. 2010;7(5):e1000244.

47. Mudie K, Jin MM, Tan, Kendall L, Addo J, Dos-Santos-Silva I, Quint J, Smeeth L, Cook S, Nitsch D, et al. Non-communicable diseases in sub-Saharan Africa: a scoping review of large cohort studies. J Glob Health. 2019;9(2):020409.

48. Nkosi V, Wichmann J, Voyi K. Chronic respiratory disease among the elderly in South Africa: any association with proximity to mine dumps? Environ Health. 2015;14:33.

49. Deveci F, Deveci SE, Turkoglu S, Turgut T, Kirkil G, Rahman S, Acik Y, Muz $\mathrm{MH}$. The prevalence of chronic obstructive pulmonary disease in Elazig, Eastern Turkey. Eur J Intern Med. 2011;22(2):172-6.

50. Ahmed R, Robinson R, Mortimer K. The epidemiology of noncommunicable respiratory disease in sub-Saharan Africa, the Middle East, and North Africa. Malawi Med J. 2017;29(2):203-11.

51. Sanni S, Hongoro C, Ndinda C, Wisdom JP. Assessment of the multisectoral approach to tobacco control policies in South Africa and Togo. BMC Public Health. 2018;18(Suppl 1):962.

52. Reddy P, James S, Sewpaul R, Yach D, Resnicow K, Sifunda S, Mthembu Z, Mbewu A. A decade of tobacco control: the South African case of politics, health policy, health promotion and behaviour change. S Afr Med J. 2013;103(11):835-40. 
53. Bousquet J, Ndiaye M, Ait-Khaled N, Annesi-Maesano I, Vignola AM. Management of chronic respiratory and allergic diseases in developing countries. Focus on sub-Saharan Africa. Allergy. 2003;58(4):265-83.

54. Stovern M, Felix O, Csavina J, Rine KP, Russell MR, Jones RM, King M, Betterton EA, Saez AE. Simulation of windblown dust transport from a mine tailings impoundment using a computational fluid dynamics model. Aeolian Res. 2014;14:75-83.

55. Wright CY, Matooane M, Oosthuizen MA, Phala N: Risk perceptions of dust and its impacts among communities living in a mining area of the Witwatersrand, South Africa. 2014.

56. Antao VC, Pinheiro GA. Surveillance for occupational respiratory diseases in developing countries. Semin Respir Crit Care Med. 2015;36(3):449-54.

57. Omland O, Wurtz ET, Aasen TB, Blanc P, Brisman JB, Miller MR, Pedersen OF, Schlunssen V, Sigsgaard T, Ulrik CS, et al. Occupational chronic obstructive pulmonary disease: a systematic literature review. Scand J Work Environ Health. 2014;40(1):19-35.

58. Fairall LR, Folb N, Timmerman V, Lombard C, Steyn K, Bachmann MO, Bateman ED, Lund C, Cornick R, Faris G, et al. Educational Outreach with an Integrated Clinical Tool for Nurse-Led Non-communicable Chronic Disease Management in Primary Care in South Africa: A Pragmatic Cluster Randomised Controlled Trial. PLoS Med. 2016;13(11):e1002178.

59. Zhang D, Qian XJ, Chu SL, Jing H, Tong ZH, Liang LR: Level and trend of respiratory diseases mortality in China from 2002 to 2016. Zhonghua Yi Xue Za Zhi 2020, 100(24):1895-1900.

60. Asaria P, Elliott P, Douglass M, Obermeyer Z, Soljak M, Majeed A, Ezzati M. Acute myocardial infarction hospital admissions and deaths in England: a national follow-back and follow-forward record-linkage study. Lancet Public Health. 2017;2(4):e191-201.

61. Sandoval Y, Thygesen K. Myocardial Infarction Type 2 and Myocardial Injury. Clin Chem. 2017;63(1):101-7.

62. Piffaretti C, Moreno-Betancur M, Lamarche-Vadel A, Rey G. Quantifying cause-related mortality by weighting multiple causes of death. Bull World Health Organ. 2016;94(12):870-9.

\section{Publisher's Note}

Springer Nature remains neutral with regard to jurisdictional claims in published maps and institutional affiliations.

Ready to submit your research? Choose BMC and benefit from:

- fast, convenient online submission

- thorough peer review by experienced researchers in your field

- rapid publication on acceptance

- support for research data, including large and complex data types

- gold Open Access which fosters wider collaboration and increased citations

- maximum visibility for your research: over 100M website views per year

At BMC, research is always in progress.

Learn more biomedcentral.com/submissions 